\title{
Cortical fMRI Activation Produced by Attentive Tracking of Moving
}

\section{Targets}

\author{
JODY C. CULHAM,${ }^{1}$ STEPHAN A. BRANDT,,${ }^{2,3}$ PATRICK CAVANAGH, ${ }^{1}$ NANCY G. KANWISHER, ${ }^{4}$ \\ ANDERS M. DALE, ${ }^{2}$ AND ROGER B. H. TOOTELL ${ }^{2}$ \\ ${ }^{1}$ Department of Psychology, Harvard University, Cambridge, Massachusetts 02138; ${ }^{2}$ Massachusetts General Hospital \\ Nuclear Magnetic Resonance Center, Charlestown, Massachusetts 02129; ${ }^{3}$ Neurologische Klinik, Charité, Humboldt \\ University, Berlin, Germany; and ${ }^{4}$ Department of Brain and Cognitive Sciences, Massachusetts Institute of Technology, \\ Cambridge, Massachusetts 02139
}

Culham, Jody C., Stephan A. Brandt, Patrick Cavanagh, Nancy G. Kanwisher, Anders M. Dale, and Roger B. H. Tootell. Cortical fMRI activation produced by attentive tracking of moving targets. J. Neurophysiol. 80: 2657-2670, 1998. Attention can be used to keep track of moving items, particularly when there are multiple targets of interest that cannot all be followed with eye movements. Functional magnetic resonance imaging ( fMRI) was used to investigate cortical regions involved in attentive tracking. Cortical flattening techniques facilitated within-subject comparisons of activation produced by attentive tracking, visual motion, discrete attention shifts, and eye movements. In the main task, subjects viewed a display of nine green "bouncing balls"' and used attention to mentally track a subset of them while fixating. At the start of each attentive-tracking condition, several target balls (e.g., $3 / 9$ ) turned red for $2 \mathrm{~s}$ and then reverted to green. Subjects then used attention to keep track of the previously indicated targets, which were otherwise indistinguishable from the nontargets. Attentive-tracking conditions alternated with passive viewing of the same display when no targets had been indicated. Subjects were pretested with an eye-movement monitor to ensure they could perform the task accurately while fixating. For seven subjects, functional activation was superimposed on each individual's cortically unfolded surface. Comparisons between attentive tracking and passive viewing revealed bilateral activation in parietal cortex (intraparietal sulcus, postcentral sulcus, superior parietal lobule, and precuneus), frontal cortex (frontal eye fields and precentral sulcus), and the MT complex (including motion-selective areas MT and MST). Attentional enhancement was absent in early visual areas and weak in the MT complex. However, in parietal and frontal areas, the signal change produced by the moving stimuli was more than doubled when items were tracked attentively. Comparisons between attentive tracking and attention shifting revealed essentially identical activation patterns that differed only in the magnitude of activation. This suggests that parietal cortex is involved not only in discrete shifts of attention between objects at different spatial locations but also in continuous " attentional pursuit" of moving objects. Attentive-tracking activation patterns were also similar, though not identical, to those produced by eye movements. Taken together, these results suggest that attentive tracking is mediated by a network of areas that includes parietal and frontal regions responsible for attention shifts and eye movements and the MT complex, thought to be responsible for motion perception. These results are consistent with theoretical models of attentive tracking as an attentional process that assigns spatial tags

The costs of publication of this article were defrayed in part by the payment of page charges. The article must therefore be hereby marked "advertisement" in accordance with 18 U.S.C. Section 1734 solely to indicate this fact. to targets and registers changes in their position, generating a highlevel percept of apparent motion.

\section{IN T R O D UCTION}

Two strategies can be employed by the visual system to enhance processing of important targets. First, eye movements can direct the high-resolution fovea to the target of interest either by discrete jumps to different targets (saccades) or by continuous visual tracking of a moving target (smooth pursuit). Second, even in the absence of eye movements, processing can be facilitated when attention is directed to the target by either discrete attentional shifts between targets ("attentional saccades") or continuous attentive tracking of one or more moving targets ("attentional pursuit"'). Although eye movements and attentional shifts have been widely investigated, little is known about attentive tracking and its relationship to these other mechanisms. To our knowledge, this paper provides the first comprehensive neuroimaging study of attentive tracking and its relationship to these associated processes.

Cognitive and neuroimaging studies of attention have focused on discrete shifts of attention such as spatial attention cueing (Posner 1980) or visual search (Treisman and Gelade 1980). However, once attention has been directed to a target of interest such as a face in a crowd, the attentional focus can be maintained on that target even as it moves. At first thought, attentive tracking may seem unnecessary because smooth-pursuit eye movements serve essentially the same function. However, in everyday life, there are frequent cases in which multiple items of importance move, preventing the sole use of eye tracking, which only offers a single focus. For example, team sports require attention to one's teammates and opponents, driving requires attention to other vehicles and pedestrians, and occupations such as air traffic control require simultaneous attention to many moving targets.

Not only can attentive tracking be used to pursue targets as they move, it also can enhance or generate the viewer's impression of motion (Cavanagh 1992; Wertheimer 1961). Attentive tracking has been suggested as one of two fundamental motion systems that have been proposed (Anstis 1980; Braddick 1980; Cavanagh 1992; Cavanagh and Mather 1989). In this view, attentive tracking is distinct 
from a passive system based on stimulus energy processed by low-level motion detectors [such as the motion-selective neurons found in the striate visual area (V1) and the extrastriate motion area (MT)]. Instead, it is based on an active system that determines high-level correspondence matching between the positions of attended features over time. Such feature tracking can generate or enhance the perception of motion for stimuli that are otherwise poor at stimulating the low-level system (e.g., apparent motion stimuli, equiluminant stimuli). For example, in the case of moving equiluminant gratings, the true speed of the grating only can be determined by using attention to track the changing position of one of its bars (Cavanagh 1992; Cavanagh et al. 1984). Just as smooth pursuit of a moving target can generate a percept of its motion arising from the outgoing signal to move the eye (efference copy) (Helmholtz 1925), attentional pursuit may generate a motion percept from the signals that keep attention locked on a target of interest (Cavanagh 1991). Psychophysical studies have suggested that attentive tracking can influence low-level motion perception (Culham and Cavanagh 1994); however, its effects appear to arise from relatively late stages of motion processing (Culham et al. 1998).

Here we used functional magnetic resonance imaging ( $\mathrm{fMRI}$ ) to investigate the neuroanatomic substrates of attentive tracking. We were interested particularly in using neuroimaging to examine the functional relationship between attentive tracking and the associated processes described above-attention shifts, eye movements, and motion perception. First, we expected some, but not necessarily complete, overlap between attentive tracking and attention shifts. Corbetta and his colleagues (1993, 1995) have proposed that the superior parietal lobe (SPL) is activated only by shifts of attention as in visual search (Corbetta et al. 1993) and the sequential direction of attention to targets within a spatial array (Corbetta et al. 1995). However, these regions may or may not be activated in attentive tracking, depending on whether similar engagement, disengagement, and shifting mechanisms (e.g., Posner and Petersen 1990) are involved when attention remains locked on a particular item or set of items that move continuously. Just as saccades and smooth pursuit activate some but not all of the same areas, it may be that "attentional saccades" and "attentional pursuit" also differ. Second, we were interested in the degree of overlap between these covert means of target selection (attention shifts and attentive tracking) and overt target selection by eye movements ( saccades and smooth pursuit). The functional similarity between attention shifts and saccades has been highly controversial, as described by Corbetta's (1998) recent comprehensive review of the literature and meta-analysis of neuroimaging results. Here we perform within-subject comparisons of attention and eye-movement tasks, including overt and covert pursuit. Third, given the theoretical links between attentive tracking and high-level motion perception, we investigated the effects of tracking on activation in motion areas. Past studies have suggested that directing global attention to motion enhances brain activity in the middle temporal (MT) and/or medial superior temporal (MST) areas of monkey cortex (Treue and Maunsell 1996) and in the homologous region of human cortex, MT+ (including both MT and MST) (Beauchamp et al. 1997; Bush et al. 1995; Corbetta et al. 1990, 1991; O'Craven et al. 1997; Rees et al. 1997). In addition, other motion-responsive areas have been identified (Dupont et al. 1994; Tootell et al. 1997) but their susceptibility to attentional influences has yet to be investigated.

We chose to use a multiple-object tracking task developed by Pylyshyn and Storm (1988) in which subjects mentally pursue several items simultaneously. Subjects viewed a display of moving balls and used only their attention (no eye movements) to keep track of several of the balls that had been briefly cued. Past reports have found that subjects can track up to four or five balls quite accurately (Pylyshyn and Storm 1988). However, attention to the target balls does not extend to locations between the items (Intriligator and Cavanagh 1992; Sears and Pylyshyn, cited in Pylyshyn 1994), and in modeling, a single attentional spotlight cannot shift fast enough to account for the high performance of the subjects (Pylyshyn and Storm 1988). Thus it has been suggested that attention can be directed to multiple spatial tags simultaneously (Pylyshyn and Storm 1988) and can provide information about the history of the tagged items (Chun and Cavanagh 1997; Kahneman et al. 1992) despite changes in position and brief periods of occlusion (Scholl and Pylyshyn 1999). We used this particular tracking task because it is indeed attention-demanding (Treisman and Wilson, cited in Treisman 1993) and is understood easily, natural, and engaging for the subjects.

These results have previously been presented in abstract form (Culham et al. 1997a,b).

\section{METHODS}

\section{Main stimulus and task: multiple-object tracking}

In the main multiple-object tracking task used to investigate attentive tracking, nine bright green "bouncing balls" (1.5 diam) appeared in Brownian-like motion within a dark gray square (20 $\times 20^{\circ}$ ) on a black background (see Fig. $1 A$ ). Each ball's trajectory was subject to random variations, producing unpredictable paths. Balls bounced off the edge of the square and repelled one another, never colliding with or occluding one another. A bull's-eye appeared in the center of the display to provide a fixation point and repelled the balls to avoid drawing fixation away. The importance of maintaining fixation was emphasized clearly to the subjects.

The experimental paradigm included two main conditions, with comparable displays but different instructions to the subjects. Instructions were given by large text labels, "attend" or "don't attend,' presented for $2 \mathrm{~s}$ at the start of each period. During attentive-tracking (attend) periods, a subset of balls (usually 3 ) to be tracked first underwent a color change to red for $2 \mathrm{~s}$. Then they changed back to the original green color such that no cue remained to distinguish them from the untracked balls. Subjects were instructed to attentively track those balls while fixating. During passive viewing (don't attend) conditions, all balls were green throughout the period, and subjects were instructed to passively watch the whole display without paying attention to any balls in particular. Except for the first $2 \mathrm{~s}$, attentive-tracking and passiveviewing stimuli were identical, and the tracked balls differed from the untracked balls only in their history not their current features. Thus any differences in the main comparison (attentive tracking vs. passive viewing) arose from the attentional task, not the stimuli. Some scans also included an additional fixation period in which the display consisted of only the fixation bull's-eye on the dark gray background. This condition provided an additional subtraction 
(passive viewing-fixation alone) to indicate regions that responded to the stimulus display in the absence of task demands.

We also examined activation produced by attentive tracking (compared with passive viewing) when the bouncing balls were equiluminant with the background. Such displays may be more sensitive at revealing attentional modulation because activity in MT + is less likely to be saturated (than with a display at high luminance contrast) (Tootell et al. 1995b) and because the perceptual effect of attending to the motion is much more dramatic (Cavanagh 1992). Four subjects were tested when the balls were equiluminant with the background, that is, they had the same brightness but a different color (green on gray). An individual subject's equiluminance point was set by making the background light gray and then rapidly alternating the colors of the background and balls and having the subject adjust the luminance of the balls until minimal borders and minimal flicker were perceived. At equiluminance, the balls appeared "jazzy" but were presented at a slightly larger size and were tracked easily with attention. As before, subjects either passively viewed the equiluminant balls or tracked a subset with their attention, and activation was compared between the two states with identical stimuli but different task demands.

\section{MRI acquisition}

Functional images were collected using a 1.5 Tesla General Electric Signa scanner with echo-planar imaging (Advanced NMR) at the Massachusetts General Hospital (MGH) Nuclear Magnetic Resonance (NMR) Center in Charlestown, MA. For most subjects $(15 / 21)$, a semicylindrical bilateral surface coil was positioned over the parietal and occipital lobes. This arrangement provided excellent signal strength in the posterior brain regions, with lower signal strength in more anterior regions. Slices typically were aligned along an oblique axis, parallel to the calcarine sulcus, to include the main regions of interest: early visual areas, motion areas, and parietal attention areas. In addition, several subjects (6/ 21 ) were tested with a head coil, which covered a larger extent of brain but with reduced signal/noise. With the head coil, slice orientation was near-horizontal, taken through superior frontal, parietal, and occipital cortex. Inferior frontal cortex, anterior temporal cortex, the cerebellum, and subcortical structures were sampled incompletely or inconsistently and will not be considered in this paper.

Functional MRI acquisitions used asymmetric spin echo pulse sequences to minimize the contribution of large blood vessels (time of repetition, TR $=2-3 \mathrm{~s}$ ). Voxel sizes were $3.125 \times 3.125 \mathrm{~mm}$ (in-plane) $\times 4-8 \mathrm{~mm}$ (slice thickness) in 12-16 slices. Each functional scan lasted 4 to 6.5 min (128-165 time points), with a given task condition lasting between 16 and $24 \mathrm{~s}$. Two or three scans were acquired for each comparison and averaged, except when the head coil was used and three to eight scans were acquired to compensate for its reduced signal.

Subjects lay comfortably on their backs within the bore of the magnet. They viewed the stimuli via a mirror that reflected images displayed on a rear-projection screen (Da-tex, Da-lite, Screen Company, Cincinnati, OH) placed perpendicular to the body at neck level. Stimuli were generated with custom software (Vision Shell, MicroML) on a Macintosh IIvx computer and displayed with a color LCD projector (Sharp XG2000). To minimize head movement, a bite bar was used for almost all subjects.

\section{Data analysis}

Altogether, data were collected for 21 subjects using two different analysis techniques. Of these, seven subjects had their brainactivation patterns rendered on cortically flattened maps to provide comparisons with other brain-mapping sessions in which they had participated previously (e.g., Tootell et al. 1996). Data from an additional 15 subjects were processed using conventional MRI analyses (without cortical flattening) to allow comparisons of activation levels in multiple conditions within the same scans.

CORTICAL FLATTENING ANALYSES. Cortical flattening (Dale and Sereno 1993; Drury et al. 1996) renders activation on the twodimensional cortical surface of each subject's "inflated" brain, which has been unfolded with minimal distortion to show both the gyri and the sulci on a contiguous surface. The inflated surfaces can be further cut and "flattened" onto a single surface to facilitate interpretation of early retinotopic areas (De Yoe et al. 1996; Engel et al. 1997; Sereno et al. 1995). These rendering techniques provide an intuitive presentation of activated regions, help disambiguate the localization of activation relative to sulcal landmarks, and enable the comparison of data from multiple sessions.

For data analyzed with cortical flattening procedures, each scan consisted of two alternating conditions of identical duration (e.g., attentive tracking vs. passive viewing or passive viewing vs. fixation alone). The phase and amplitude of the activation was determined with a Fourier analysis of the time series from each voxel. An $F$ test determined regions with significantly greater amplitude at the appropriate frequency for the paradigm (compared with other frequencies ). Positive activation was rendered on regions that were modulated in phase with the paradigm alternation, after shifting the phase angle to compensate for the hemodynamic delay of $4 \mathrm{~s}$ (Dale and Buckner 1997). Deactivation (regions modulated in antiphase) also was rendered but was rare and, for simplicity, is not shown in the figures here. The resulting $P$ values were smoothed with 10 iterations of a box-car filter, leading to spatial smearing on the order of $3 \mathrm{~mm}$ (half-width, half-maximum).

To obtain group Talairach coordinates (Talairach and Tournoux 1988), we first determined the mean coordinate location of each activated region in each of the seven flat-mapped subjects. We then averaged the coordinates of corresponding regions across subjects. The identity of most activation foci was generally clear from either functional criteria (e.g., MT+) or sulcal landmarks (e.g., frontal eye fields) (Paus 1996). However, parietal regions were often contiguous, making segregation more difficult. Where possible, activation thresholds were raised until regions became discrete, and then average coordinates were determined for activation within each subregion, as determined by sulcal landmarks (intraparietal and postcentral sulci). Increasing the threshold often failed to segregate activity in superior parietal lobule from that in the intraparietal sulcus, so only one coordinate is given for this focus.

CONVENTIONAL ANALYSES. The results from the subjects analyzed with cortical flattening techniques were corroborated by data from other subjects (11 using the surface coil, 4 using the head coil) whose data were analyzed with conventional techniques. These conventional analyses used custom software (XDS, Tim Davis ) to superimpose functional activation on high-resolution T1 slices. The significance level of voxels in the subtractions was determined using the Kolmolgorov-Smirnov test (a nonparametric variant of the $t$-test). Image sequences were examined for head motion (artifactual activation at brain edges or motion seen in a cinematic loop). When head motion was observed, either a threedimensional motion-correction algorithm (automatic image registration or AIR) (Jiang et al. 1995) was applied or, if the motion was $>2 \mathrm{~mm}$, the data were discarded.

Six conventionally analyzed subjects were run in a multiplecondition paradigm in which each scan included attentive-tracking and passive-viewing conditions interspersed with fixation conditions. Such designs can reveal the modulation by attention relative to the degree of visual activation produced by the display itself. Although data from the flat-mapped subjects will be emphasized here, data from the conventionally analyzed subjects were also highly consistent with the trends reported here. 

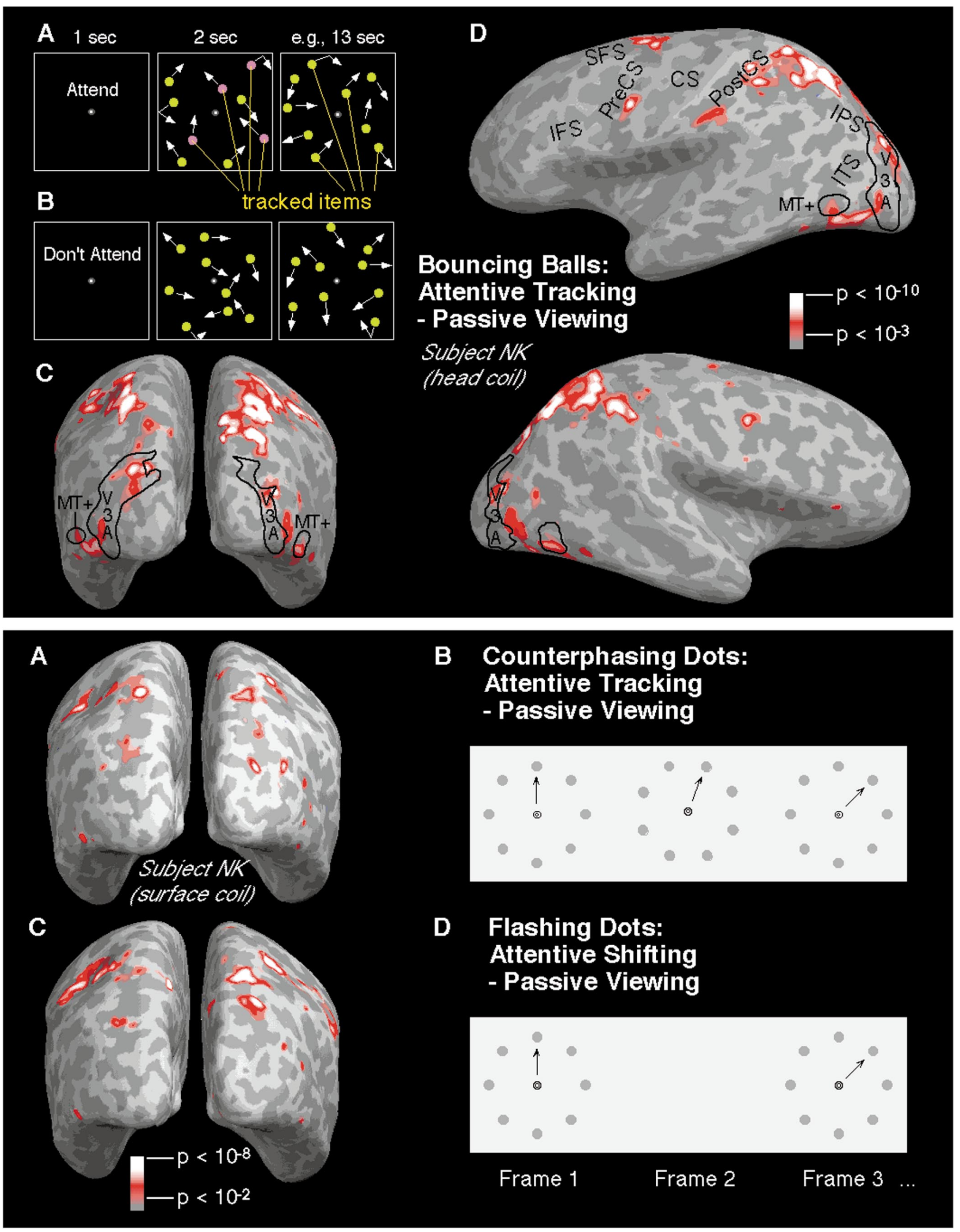


\section{Subjects}

All subjects were young $(<40)$ and right-handed. All had good health and clear vision. Subjects whose data were analyzed with cortical flattening techniques (flat-mapped subjects) were researchers in the MGH NMR Center and Harvard Psychology Department. Subjects analyzed with conventional techniques also included naive, paid student volunteers who responded to an advertisement on Harvard and MIT newsgroups. Informed consent was obtained from all subjects (with procedures approved by the Harvard University Committee on the Use of Human Subjects in Research and Massachusetts General Hospital Subcommittee on Human Studies).

Before the MR scanning session, subjects were given practice trials, and their accuracy was measured to ensure they could perform the attentive-tracking task adequately. In each of 10 trials, each subject tracked a briefly cued subset of balls for the duration of the interval to be used during the scanning session ( 13 or $21 \mathrm{~s}$ ). Then a single ball turned white, and the subject indicated whether it was a tracked target or an untracked distractor. After instructions, training and practice trials, all subjects could perform the task accurately ( $\geq 90 \%$ accuracy). Subjects who were more familiar with the task were assigned to track more balls than novice subjects to keep the task sufficiently demanding. Three subjects tracked 3/ 9 balls; three subjects tracked $4 / 9$ balls; and one overpracticed author, J.C., tracked 5/10 balls ).

All of the flat-mapped participants were regular fMRI subjects, highly experienced at maintaining fixation and a stable head position. Thus it is unlikely that the activation observed in their data results from unwanted eye movements. Nonetheless, we wanted to be fully certain that subjects were not moving their eyes while performing the task. Therefore, eye movements were monitored in three flat-mapped subjects during fMRI acquisition using a binocular infrared pupil-tracker (Ober2, Permobil) adapted to work within the magnet at a sampling frequency of $100 \mathrm{~Hz}$ (Brandt et al. 1997b). Although the radio frequency pulses of the magnet produced substantial artifacts in the eye-movement traces, these artifacts were distinguished easily from real eye movements by their regularity, amplitude, and physiologically impossible high velocity. Calibrations suggested that saccades of $\geq 1^{\circ}$ could be detected readily in the presence of the artifacts. Analyses of these eyemovement traces indicated that subjects did indeed maintain accurate fixation (with no saccades $>1^{\circ}$, no smooth deviations $>2^{\circ}$, and no apparent differences between conditions). No differences in the pattern of fMRI activation were noted between these subjects and the unmonitored subjects.

All other subjects also were screened for accurate tracking and accurate fixation during a 45-min pilot session before the MRI session. The attentive-tracking task was described and subjects were given practice trials until they were comfortable with the task. Their attentive-tracking accuracy was measured, and their eye movements were recorded outside the magnet to make sure that they could perform the task accurately for 5-s intervals while maintaining fixation. Subjects who had poor accuracy $(<90 \%$ correct) or frequent or unusual eye movements were not tested further. Most subjects tracked three of nine balls, though a few practiced observers tracked four of nine balls.

\section{Additional stimuli and task: attentive tracking and attention shifting}

We also employed a second display that allowed us to compare continuous attentive tracking with discrete attentional shifts. We designed two sets of stimuli that were very similar in their visual properties, one of which was appropriate for attentive tracking and one that implicated traditional shifts of attention.

ATTENTIVE TRACKING OF COUNTERPHASING DOTS. As shown in Fig. $2 B$, a ring of disks was presented around a circle. The positions of the disks alternated between two sets of locations with no interstimulus interval (ISI), such that the direction of rotation was inherently ambiguous but could be disambiguated with attentional tracking (Wertheimer 1961). That is, subjects used their attention to follow a single dot in one assigned direction or the other (making a full rotation every 8 or $16 \mathrm{~s}$ ). Such attentive tracking led to the perception that the tracked dot continuously moved (in apparent motion) around the ring despite the absence of any net motion energy in the physical stimulus. We compared attentive tracking of the counterphasing dots (16-s periods) with passive viewing of the same counterphasing stimulus (16-s periods).

ATTENTION SHIFTING WITH FLASHING DOTS. With a minor modification, the attentive-tracking component could be eliminated from the counterphase tracking stimulus just described. As shown in Fig. $2 D$, when the disks flashed on and off in the same locations with an ISI equal to the duration of a single frame, attention could be shifted from one dot to another between frames (rotating at the same rate as in the attentive-tracking condition). Unlike the counterphase tracking condition, this did not produce a percept of motion; rather, subjectively it seemed as though attention was being allocated sequentially to different dots. Attention shifting was compared with passive viewing of the flashing stimulus.

The counterphase tracking and attentional shifting configurations were very similar in the required shifts of attention and in their

FIG. 1. Bouncing balls display and typical regions of activation produced by the comparison of attentive tracking $(A)$ and passive viewing $(B)$. Each condition period began with a text instruction. For attentive-tracking conditions, a subset of balls (indicated here by yellow lines not present in the actual display) were cued in red for $2 \mathrm{~s}$ and then tracked with attention for the remainder of the period. Representative activation from one subject, $N K$, tested with the head coil (while tracking 4/9 balls) is presented on inflated cortical surfaces (gyri in light gray; sulci in dark gray). Three views are shown: posterior view of both hemispheres ( $C$, left hemisphere shown on left side) and the lateral view of the left and right hemispheres $(D)$. Color scale indicates the significance level of activation in red $\left(P<0.001\right.$ for dim red, $P<10^{-10}$ for bright white $)$. These thresholds apply to other figures in this paper, except where otherwise indicated. Deactivation (i.e., a decrease in the MR signal) rarely was observed in this comparison and is not shown. Sulci are labeled in black text: SFS, superior frontal sulcus; IFS, inferior frontal sulcus; PreCS, precentral sulcus; CS, central sulcus; PostCS, postcentral sulcus; IPS, intraparietal sulcus; ITS, inferior temporal sulcus. The MT+ complex, defined by a functional motion localizer, and visual area V3A, defined by field sign maps, are outlined.

FIG. 2. Regions of activation produced by counterphase tracking ( $A$ and $B$ ) and attentive shifting $(C$ and $D)$ for the same subject as in Fig. 1. In the counterphase tracking task $(B)$, a ring of balls alternated between 2 sets of positions with no interstimulus interval or ISI). At each transition, subjects shifted their attention by 1 position in 1 direction, as indicated by the black arrows which were not actually present in the display. With attentive tracking, the counterphase display was disambiguated such that subjects perceived that the attended ball was rotating around the ring in the tracked direction. In the attention shifting task $(D)$, the ring of balls simply flashed in place (with flashes separated by a blank ISI), and subjects shifted their attention by 1 position per flash. Although 2 tasks were similar in their displays and demands, they were perceptually different: attentive tracking involved the continuous attentional pursuit of a single dot, whereas attention shifting involved discrete shifts of attention between discrete locations. Nonetheless, regions of activation were similar. 
low-level composition (in Fourier terms, a flashing stimulus is the sum of counterphasing and stationary stimuli). However, only with the counterphasing stimulus did subjects report the percept of motion of a single dot. Thus any brain areas responsive to attentionbased motion per se would be expected to be activated in the attentive-tracking condition but not the attention-shifting condition. Five subjects (all tested with a surface coil, 2 flat-mapped) participated in both tasks. To provide direct comparisons between the tasks, two of the subjects participated in a $2 \times 2$, stimulus (counterphasing vs. flashing) $\times$ task (passive viewing vs. attending) design, which enabled us to make direct subtractions between attention tracking versus shifting.

\section{Comparison tasks}

The following comparisons were available for many flat-mapped subjects.

FIELD SIGN MAPS. For five flat-mapped subjects, retinotopic visual areas had been mapped using responses to phase-encoded stimuli varying in polar angle or eccentricity (see Sereno et al. 1995; Tootell et al. 1997 for details ) and were superimposed on maps of occipital cortex that had been flattened fully (by making virtual cuts along the calcarine sulcus ). Boundaries between visual areas, V1, V2, V3/VP, V3A, and V4v, were determined by the transitions between mirror-image retinotopic representations (occurring at either the horizontal or vertical meridia).

LOW-CONTRAST MOVING VERSUS STATIONARY RINGS. For all 7 flattened subjects and 9/15 conventionally analyzed subjects, motion-selective areas were defined by the comparison of moving versus stationary rings, as described by Tootell et al. (1995b). Using low-contrast stimuli, typically only the MT+ complex and sometimes V3A (Tootell et al. 1997) were activated.

EYE MOVEMENTS. Four of the subjects also participated in eye-movement studies by Brandt and his colleagues (1997a). This allowed us to compare the overlap in activation due to attentive tracking versus eye movements (Brandt et al. 1997a; Culham et al. 1997a). In the saccade task, subjects made visually guided saccades to a small $\left(0.2^{\circ}\right)$ red dot that jumped unpredictably between seven horizontal positions at 1 or $2 \mathrm{~Hz}$. In the smooth-pursuit task, subjects pursued the dot as it oscillated horizontally at $10-30^{\circ} \%$ s. In each case, the eye-movement task was compared with fixation. To minimize artifactual retinal stimulation, neutral density filters were placed over the projector to reduce the luminance of the dot and eliminate all other sources of light.

\section{RES ULTS}

Figure 1 shows the activation for attentive tracking, compared with passive viewing, for one cortically flattened subject. These data are representative of the typical pattern of activation. To summarize the consistency across subjects, Table 1 lists all regions observed in two or more subjects, their Talairach coordinates, and their frequency by hemisphere. Figure 2 provides a comparison of the counterphase tracking and attention shifting tasks in the same subject. Figures 3 and 4 show data from the main task for three additional subjects.

\section{Parietal areas}

The most reliable and robust activation during multipleobject tracking was observed in parietal cortex. Typically, an arc of activation appeared along the intraparietal sulcus (IPS), running between the transverse occipital sulcus (TOS) at the posterior end (usually anterior to V3A) and
TABLE 1. Number of flat-mapped subjects showing significant activation in brain regions of interest for the comparison of attentive tracking and passive viewing

\begin{tabular}{|c|c|c|}
\hline Region & Left Hemisphere & Right Hemisphere \\
\hline \multicolumn{3}{|l|}{ Occipitotemporal areas } \\
\hline $\mathrm{MT}+$ & $\begin{array}{c}5 / 7 \\
-46.4,-73.5,-2.3\end{array}$ & $\begin{array}{c}5 / 7 \\
44.2,-67.3,-0.7\end{array}$ \\
\hline Lateral occipital & $5 / 7$ & $6 / 7$ \\
\hline cortex & $-37.5,-82.1,3.8$ & $36.8,-80.5,11.4$ \\
\hline Parieto-insular cortex & $0 / 7$ & $\begin{array}{c}3 / 7 \\
53.2,-36.5,36\end{array}$ \\
\hline \multicolumn{3}{|l|}{ Parietal areas } \\
\hline Intraparietal sulcus & $7 / 7$ & $7 / 7$ \\
\hline $\begin{array}{l}\text { Anterior focus (may } \\
\text { include SPL) }\end{array}$ & $-28.8,-61.6,50.7$ & $18.5,-66.9,50.9$ \\
\hline $\begin{array}{l}\text { Posterior focus } \\
\text { (near TOS) }\end{array}$ & $-31.1,-78.9,22.4$ & $23.0,-83.4,26.1$ \\
\hline $\begin{array}{l}\text { Superior parietal } \\
\text { lobule (included } \\
\text { with anterior } \\
\text { focus of IPS) }\end{array}$ & $6 / 7$ & $6 / 7$ \\
\hline Precuneus & $5 / 7$ & $5 / 7$ \\
\hline $\begin{array}{l}\text { (posterior to } \\
\text { ascending band of } \\
\text { cingulate) }\end{array}$ & $-17.5,-69.5,69.1$ & $9.55,-63.5,76.2$ \\
\hline Postcentral sulcus & $7 / 7$ & $7 / 7$ \\
\hline & $-42.9,-38.6,44.4$ & $37.5,-40.0,47.6$ \\
\hline \multicolumn{3}{|l|}{ Frontal areas } \\
\hline Frontal eye fields & $\mathrm{HC}: 2 / 2$ & $\mathrm{HC}: 2 / 2$ \\
\hline (junction of & $\mathrm{SC}: 2 / 5$ & SC: $3 / 5$ \\
\hline $\begin{array}{l}\text { PreCS and } \\
\text { superior frontal } \\
\text { sulcus) }\end{array}$ & $-26.7,-11.3,59.5$ & $23.9,-10.3,56.9$ \\
\hline Inferior precentral & $\mathrm{HC}: 2 / 2$ & HC: $2 / 2$ \\
\hline sulcus & SC: $2 / 5$ & SC: $1 / 5$ \\
\hline & $-53.9,0.7,35.6$ & $45.2,-3.1,36.5$ \\
\hline Supplementary motor & $\mathrm{HC}: 1 / 2$ & $\mathrm{HC}: 1 / 2$ \\
\hline area and/or & SC: $1 / 5$ & SC: $0 / 5$ \\
\hline $\begin{array}{l}\text { supplementary } \\
\text { eye fields }\end{array}$ & $-6.0,0.7,57.5$ & $6.8,-0.3,58.8$ \\
\hline
\end{tabular}

Only areas that were observed in two or more subjects are given. Due to the poor resolution of the surface coil for anterior areas, head coil (HC) and surface coil (SC) data are listed separately for frontal areas. Coordinates indicate the averaged center of activation in stereotaxic space (Talairach and Tournoux 1988); ( $x$, left-right; $y$, posterior-anterior, origin at anterior commisure; $z$, inferior-superior). $P<0.001$, significant activation. Total number of subjects was seven.

extending anteriorly into the junction (Duvernoy 1991) between the IPS and postcentral sulcus (PostCS) and into the inferior PostCS. In addition, activation frequently also extended medially from the IPS into the superior parietal lobule (e.g., Fig. 1C, right hemisphere). A precuneus focus also was observed frequently just posterior to the ascending band of the cingulate sulcus (Fig. 3A, medial view). As significance thresholds were raised, the IPS activations became more distinct, often falling into two or three foci. Typically, one focus was in the IPS, near its intersection with the TOS (anterior to V3A) and another one or two were more anterior, midway up the IPS and/or in the PostCS.

\section{Frontal areas}

Several areas of frontal cortex were activated reliably in subjects tested with a head coil and were sometimes strong 


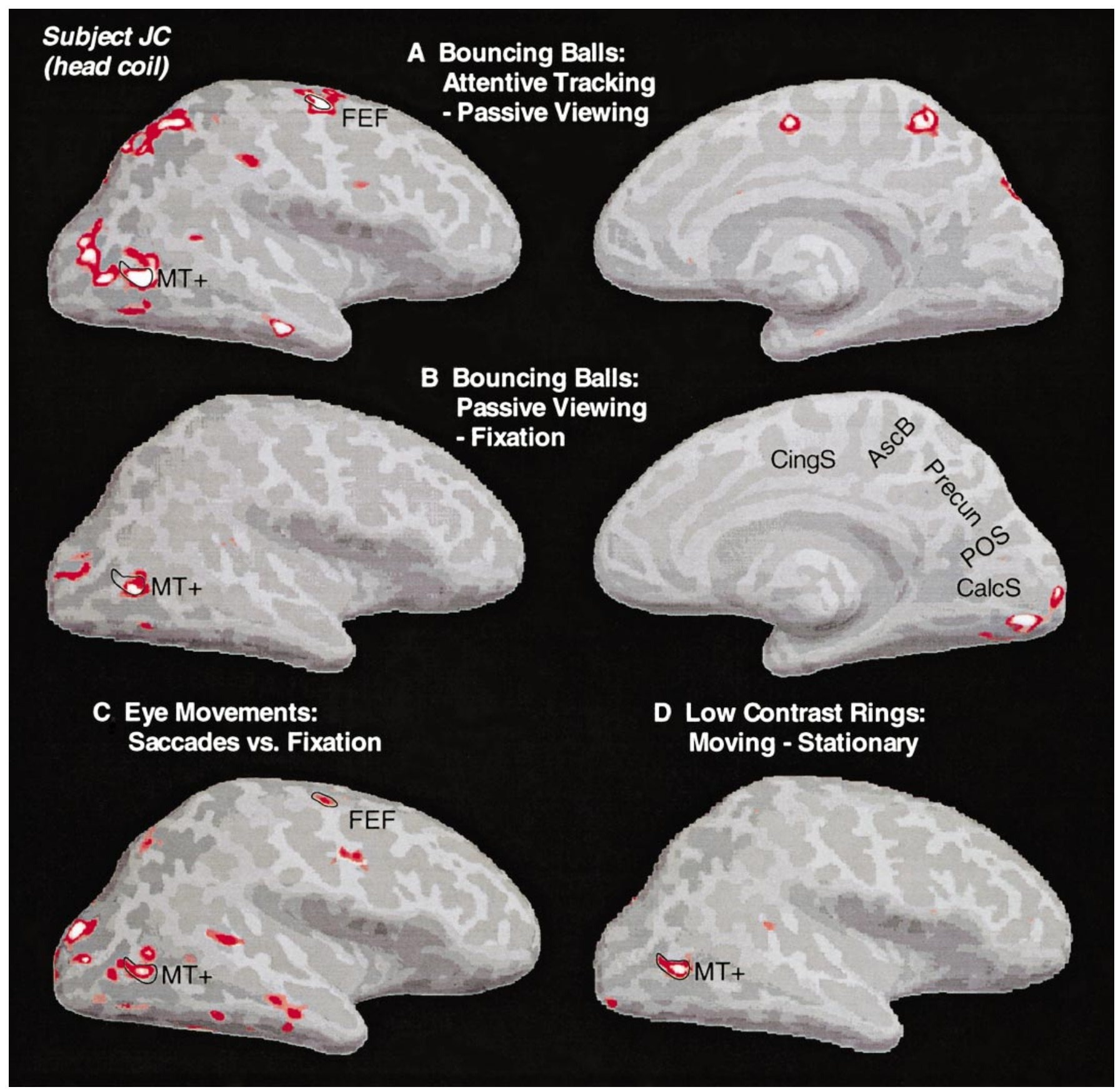

FIG. 3. Data for a 2 nd subject are shown for the comparison of attentive tracking (of $5 / 10$ balls) vs. passive viewing of the bouncing balls $(A)$, the comparison of passive viewing of the bouncing balls vs. fixation alone with no balls (B), unpredictable reflexive saccades vs. fixation (Brandt et al. 1997a) (C), indicating the location of the frontal eye fields (FEF), and the motion localizer with MT+ outlined (D). Sulci and regions in the medial surface of the brain are indicated by black text: CalcS, calcarine sulcus; POS, parieto-occipital sulcus; CingS, cingulate sulcus; AscB, ascending band of the cingulate sulcus; Precun, precuneus (region between POS and AscB).

enough to appear even with the surface coil placed at the occipital pole. Although only two flat-mapped subjects were tested with a head coil, these areas also were observed in head coil scans of four conventionally analyzed subjects and all eight subjects who participated in a separate parametric experiment (Culham et al. 1997c). All subjects tested with a head coil showed activation of the frontal eye fields (FEF), also activated by saccades (compare Fig. 3, $A$ and $C$ ), at the junction of the precentral sulcus (PreCS) and the superior frontal sulcus (Paus
1996). Frequently, a second distinct focus also was found several centimeters lower in the PreCS (Figs. $1 D$ and $3 A$ ). Two subjects also showed activation in a medial frontal area, presumably the supplementary motor area (SMA) and/or supplementary eye fields (SEF) (Fig. 3A, medial view).

\section{Occipitotemporal (visual/motion) areas}

When attention was directed to the tracked items, most subjects showed modulation in $\mathrm{MT}+$, defined independently 


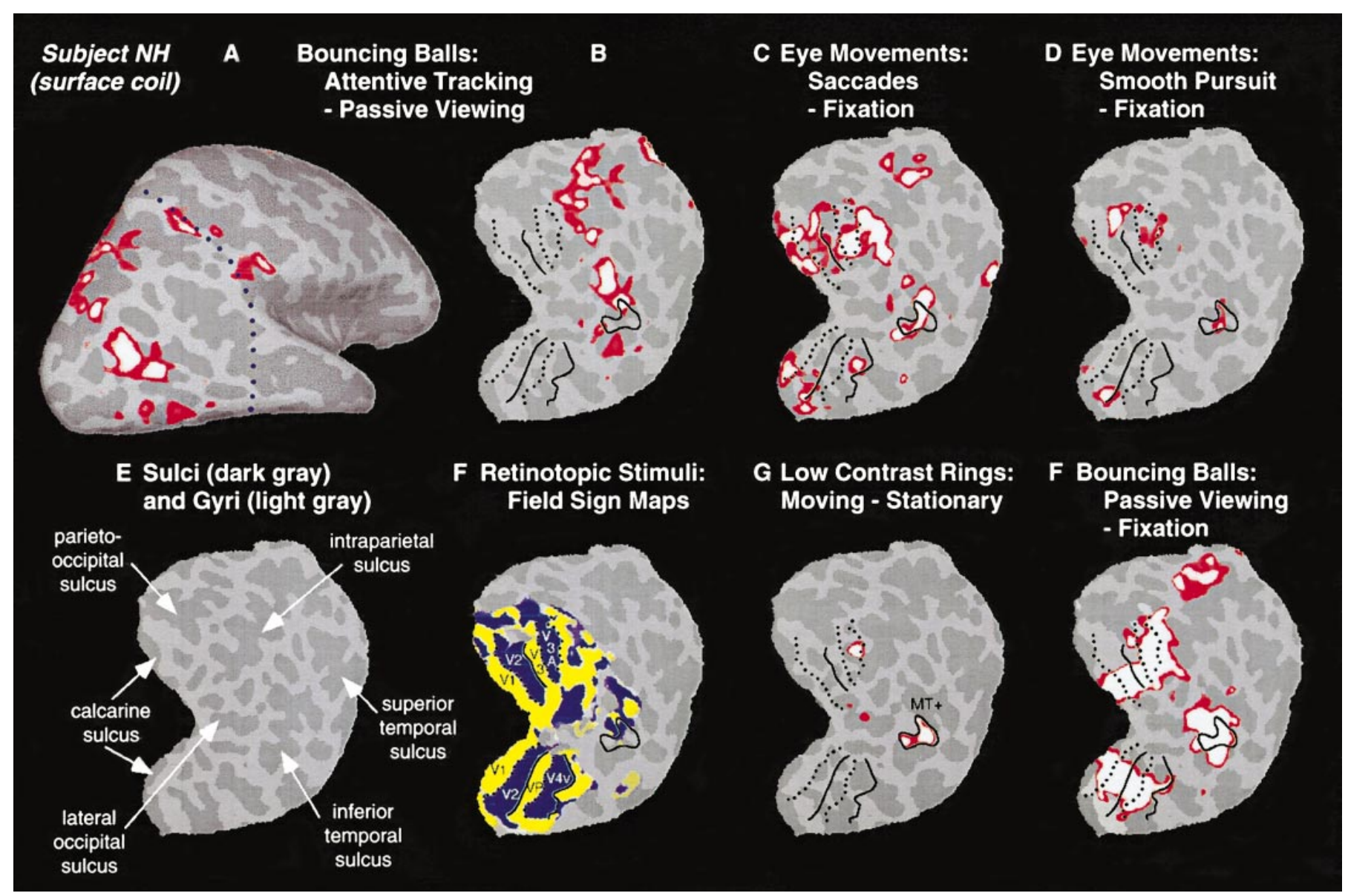

FIG. 4. A: activation produced by attentive tracking of $3 / 9$ balls (vs. passive viewing), shown from a posterior-lateral view of the right hemisphere of a 3 rd subject. $B$ : data in $A$ have been rendered to produce a fully flattened map of posterior cortex by cutting along the dark blue dots in $A$ (and on the medial surface along the calcarine sulcus and anterior to the parieto-occipital sulcus, not shown). $C$ : saccades vs. fixation. $D$ : smooth pursuit vs. fixation (Brandt et al. 1997a). For comparison, the sulci are labeled in $E$ and visual field sign maps are shown in $F$ with lines to indicate the horizontal $(-)$ and vertical meridia $(\cdots)$, which delineate retinotopic visual areas, V1, V2, V3/VP, V3A, and V4v. G: activation in $\mathrm{MT}+$ (outlined), as determined by the motion localizer (higher thresholds were used to isolate MT and V3A, red $=P$ $<10^{-10}$, white $=10^{-17}$ ). $H$ : passive viewing of the bouncing balls vs. fixation only.

by the motion area localizer (e.g., compare Fig. 3, $A$ and $D)$. However, an attentional response in $\mathrm{MT}+$ was absent in 4/22 subjects, and even when present, it was typically weak (a $0.3 \%$ MR signal change on average). Furthermore, the response in MT+ was not enhanced when the balls were made equiluminant to the background. This suggests that the weak activity did not result from a "ceiling effect" due to the high luminance contrast in the original comparison. Taken together, the evidence suggests that attentive-tracking produces only modest effects on the activation in MT+.

Although visual area V3A also has been shown to be motion selective (Tootell et al. 1997), it was activated inconsistently by attentive tracking. When available ( 5 subjects), the location of V3A was determined using field sign maps (Fig. $4 F$ ). For two of the five subjects, V3A was activated (Fig. $1 C$ ); for three others, no V3A activation was observed (e.g., Fig. 4B). More consistently, activation produced by attentive tracking appeared just anterior to V3A (Fig. 1C, right hemisphere; Fig. $4 B$ ). Attentive tracking produced no activation in other classically retinotopic visual areas (V1, $\mathrm{V} 2, \mathrm{~V} 3 / \mathrm{VP}, \mathrm{V} 4 \mathrm{v})$. Activation frequently was observed in a region of the lateral occipital cortex, between $\mathrm{MT}+$ and V3A (Figs. 1, 3A, and $4 B$ ).

\section{Comparisons with eye movements}

We observed several regions of overlap between attentive tracking and eye movements, particularly saccades. Overlap was observed in MT + as well as in the anterior IPS/PostCS, SPL, and FEF. However, several differences were also notable (compare Fig. 4, $B-D$ ). First, peripheral representations of early retinotopic areas (V1/V2/V3/VP) were activated by the retinal motion generated by saccades but never were activated by attentive tracking. Second, parieto-insular cortex (in the posterior Sylvian fissure) was reliably activated by saccades and, to a lesser degree, smooth pursuit; yet this region was activated inconsistently in attentive tracking (3/ 7 subjects, always in the right hemisphere). Third, even within the parietal lobe, a posterior focus was activated more strongly with eye-movement tasks, whereas an anterior focus was activated more strongly with the attentive-tracking task. 

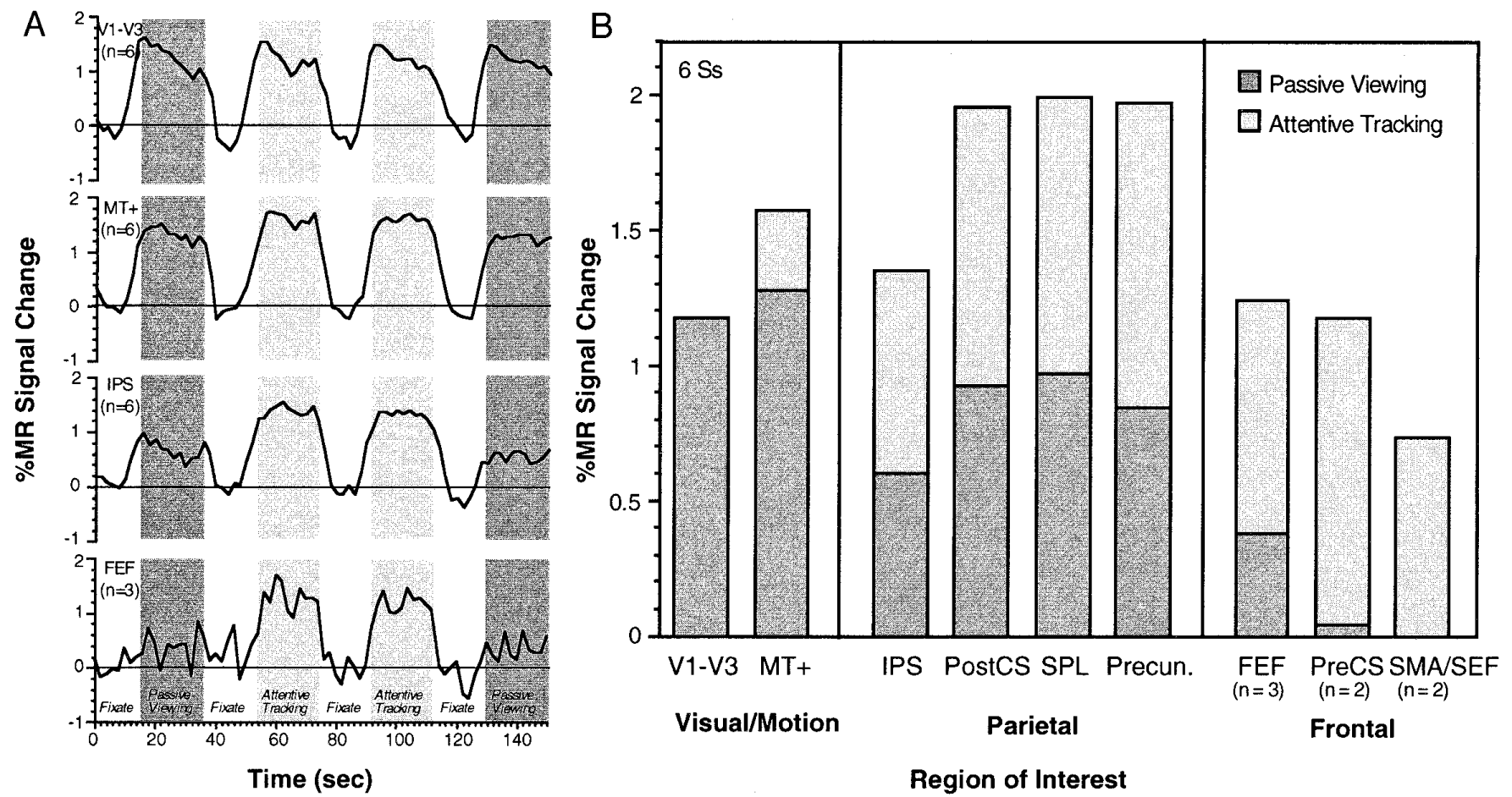

FIG. 5. Degree of activation produced by attentional modulation relative to passive visual stimulation in activated regions of interest for 6 subjects. A: sample averaged time courses. Sequence shown is based on an average across 4 or 6 repetitions of that sequence in all subjects for whom the region could be defined. Baseline of 0 is taken as the average signal during fixation-only periods, and all signal changes were calculated as a percentage of that value. Images were sampled once every $2 \mathrm{~s}$, and the time courses have been shifted to compensate for the hemodynamic delay. $B$ : activation data are summarized for all regions by plotting the average signal change for passive viewing and attentive tracking relative to a baseline of fixation alone. Activation levels for attentive tracking (light gray) are stacked on activation for passive viewing (dark gray). Visual/motion and parietal data are taken for all 6 subjects. Because 5/6 subjects were tested with the surface coil, there was low signal:noise in anterior areas; nevertheless, in several cases, frontal activation still appeared and is shown for those subjects.

\section{Comparisons with passive viewing}

Does attention simply boost processing in regions activated by the visual processing of the display, producing "more of the same" activation? Or do new areas become activated when attention is required? Compare the regional activations during attentive tracking (vs. passive viewing) in Fig. $3 A$ with those produced by passive viewing of the bouncing balls (vs. fixation with no visual stimulation) in Fig. $3 B$. Although passive viewing of the bouncing balls activates early visual and motion areas, many of the parietal and frontal foci were activated poorly by the visual stimuli in the absence of attentional demands.

We examined these trends in the time-course data from six of the conventionally analyzed subjects who had been presented with attentive-tracking, passive-viewing, and fixation conditions within the same scan. Time courses were analyzed for all areas that showed either a visual response or an attentional one. Regions of interest were defined for visual cortical areas, V1-V3 (defined by a visual response demonstrated by the subtraction of passive viewing minus fixation alone) and MT+ (defined by the motion localizer), and for the parietal and frontal regions activated by the attentive-tracking task (defined by attentive tracking vs. passive viewing). In these regions, time courses were obtained (for all voxels within a region with activation significant at $P<$ 0.001 ), as shown for several sample regions in Fig. 5A.
These time courses were used to calculate the signal change during passive-viewing and attentive-tracking periods relative to a fixation only baseline, as in Fig. $5 B$.

In both the raw time courses and the summary graph, it is clear that 1 ) early visual areas show relatively strong visual activation with weak attentional modulation, 2) parietal areas show moderate visual activation and strong attentional modulation, and 3) frontal areas show little or no visual activation and relatively strong attentional modulation. This pattern suggests that attention does not simply amplify preexisting processing but does generate activity in otherwise inactive regions.

Also note that in the time courses, additional activation during attentive-tracking periods is sustained throughout the period. This confirms that activation did not arise from minor stimulus differences in the brief initial cueing period and agrees with subjects' reports that they could maintain tracking through the interval.

\section{Comparisons of attentive tracking with attentive shifting}

We also examined two additional tasks that involved tracking a single dot in a counterphasing display (Fig. 2B) or shifting attention between dots in a flashing array. Both tasks (each compared with passive viewing) activated a similar set of brain regions as the multiple-object tracking task (compare Figs. $1 C$ and 2, $A$ and $C$ ), though with relatively 
weaker activation in motion-related areas $(\mathrm{MT}+, \mathrm{V} 3 \mathrm{~A}$, lateral occipital cortex).

Attentive tracking and attention shifting showed considerable overlap in activation. Somewhat stronger activation in the IPS and PostCS was observed for attention shifts (compared with passive viewing) than for attentive tracking (compared with passive viewing) as seen, for example, in the comparison between Fig. 2, $A$ and $C$. This difference also was observed in direct comparisons between the two tasks (attention shifting-attentive tracking) in two subjects, consistent with subjects' reports that shifting seemed more difficult than attentive tracking. In the reverse comparison (attentive tracking-attention shifting), no activation sites were observed in attentive tracking that were not found in attentive shifting, either by indirect comparisons of the levels of activation in the two tasks ( 3 subjects) or by a direct subtraction between them ( 2 subjects ). During passive viewing of the stimuli, slightly greater activation was produced by the counterphasing display than by the flashing display, indicating that the greater activation for shifting versus tracking was not due to any stimulus differences. Taken together, these data suggest that attentive tracking shares the same underlying mechanisms tapped by shifts of attention.

Although deactivation rarely was seen with the bouncingballs task, it was observed frequently in both attentive tracking of counterphase dots and attention-shifting conditions. Deactivation (i.e., less activation during active attentional conditions than during passive viewing) commonly was observed in early visual cortical areas (V1/V2/V3/ VP), particularly around the confluent foveal representation, suggesting that central visual processing may be reduced during peripheral attention.

\section{IS C USS I ON}

The functional imaging data presented here demonstrate that numerous cortical regions are involved in attentive tracking. When subjects mentally tracked a subset of moving targets using attention, we observed activity in a number of areas that also were activated by attention shifts, gaze shifts, and motion perception.

\section{Attentive tracking and attention shifting}

The most striking activation produced by attentive tracking (relative to passive viewing) was along an arc of parietal cortex, running within the IPS from the parietooccipital junction to the PostCS and including more medial structures in the SPL and precuneus. All subjects showed a robust enhancement of the activity in these regions, approximately doubling the activation produced by the presence of the stimuli alone. Indeed, parietal cortex has many of the properties that would be necessary for attentive tracking. In a comprehensive review of apparent motion phenomena, Dawson (1991) postulates a fundamental role of the SPL, area 7, (along with motion areas, including MT and MST) in a network that uses attentional tags to match correspondences (i.e., attentive tracking). He proposes that the SPL has the essential properties that would be necessary for attentive tracking: sensitivity to individuated elements, large receptive fields, object-tracking (eye movement) responses, multimodal processing, and a strong involvement in attention. Our fMRI data suggests that attentive-tracking foci are not limited to the SPL but also include adjacent parietal regions in the IPS and PostCS.

The hypothesis that parietal cortex plays a key role in attentive tracking is well supported by recent neuropsychological evidence. Two parietal patients tested by Michel et al. (1997) showed impaired attentive-tracking performance in the bouncing-balls task used here. One patient had both a left parietal lesion centered around the precuneus and a posterior split of the corpus callosum. As expected from the isolated left hemisphere damage (with no possible compensation from the intact right hemisphere because of the callosal disconnection), the patient was impaired severely at attentive tracking in the right visual hemifield. A second patient with Balint's syndrome (Balint 1909) due to bilateral occipitoparietal damage could track one ball when only two were present but could not do the task when more targets or distractors were added. These results suggest that parietal cortex is necessary for attentive tracking and argue against any suggestion that the activation we observed arises from a nonessential process (e.g., general arousal).

Our activated parietal regions closely matched those observed in neuroimaging with attention shifting tasks. Corbetta and colleagues originally reported that shifts in attention activated the superior parietal lobule in studies using positron emission tomography (PET) (Corbetta et al. 1993, 1995), and they recently have localized the activity more precisely to the IPS and PostCS using fMRI (Corbetta $1998)$. We conducted a direct comparison between an attentive-tracking task and an attention-shifting task that used comparable stimuli. The comparison revealed no activation specific to attentive tracking per se, suggesting that parietal cortex is involved not only in shifting attention between different objects at different locations but also in maintaining attention on a single object or multiple objects as they move. Parietal activation during the active condition cannot be attributed to shifts of attention between multiple tracked objects because it also occurred for the attentive tracking of a single item (Culham et al. 1997c). It also seems unlikely that attentive tracking occurs in discrete steps for each specific target, based on psychophysical evidence that subjects represent the smoothly interpolated position of an attentively tracked stimulus in a counterphasing display, as in Fig. $2 B$ (Shioiri and Cavanagh 1996).

Traditional models of discrete attention shifts include several steps, namely the disengagement, shifting and re-engagement of attention, with parietal cortex postulated to be particularly important in disengagement (Posner and Petersen 1990). However, in the case of a continuous attentivetracking task, it is less clear how such mechanisms would act. One possibility is that parietal cortex is important in assigning spatial tags to multiple potential targets (Pylyshyn 1989) toward which attention can be directed or suppressed in the intact but not damaged brain (Balint 1909; Michel et al. 1997). Given that regions of the IPS also respond to nonspatial attention tasks (temporal attention to a foveal letter stream) but not difficult nonvisual tasks, they may even be sites of general visual attention (Wojciulik and Kanwisher 1998).

Attentive tracking also produced activation in three frontal 
regions. The strongest activation was observed in the FEF, an area also activated by attention shifting (Corbetta 1998; Corbetta et al. 1993), visual search (Miyauchi et al. 1996), and spatial memory (Jonides et al. 1993). Frontal eye fields also may be activated simply by the requirement to maintain fixation (Culham et al. 1997c; Petit et al. 1995). Although both attentive-tracking and passive-viewing conditions required fixation, which presumably should cancel out in the subtraction, the maintenance of fixation may be more difficult during peripheral attention demands. In addition, a distinct second region appeared in the inferior PreCS. Activation in the FEF may extend into the inferior branch of the PreCS (Petit et al. 1996), and pursuit-related activity has been reported in the inferior PreCS, below that observed for saccades (Petit et al. 1997). However, our inferior PreCS activation was never spatially contiguous with the FEF proper. It appeared lower in the sulcus (Table 1) (Culham et al. $1997 \mathrm{c}$ ) than the previously reported eye-movement activation (Paus 1996), consistent with an inferior focus shown to be more activated by attention than saccades (Corbetta 1997). Furthermore, our data from a subsequent parametric investigation also indicate functional differences between the areas we have designated FEF and inferior PreCS (Culham et al. 1997c). The SMA/SEF was inconsistently activated, though here it cannot be attributed to motor response requirements as with previous results (Corbetta et al. 1993). Unlike other studies of attention (Corbetta et al. 1990, 1991, 1993; Posner et al. 1988), we observed negligible anterior cingulate activity. The anterior cingulate appears to be involved in response selection/competition (Carter et al. 1998; Corbetta et al. 1991), which was not a component of our attentive-tracking tasks.

\section{Attentive tracking and eye movements}

We are confident that the activation we observed was not an artifact of undesired eye movements, even for "eyemovement areas"' such as the FEF. All subjects were trained carefully and screened for accurate fixation before scanning. In addition, three subjects whose eye movements were monitored during fMRI data acquisition showed excellent fixation and typical activation patterns. Furthermore, early visual areas and parieto-insular cortex typically were activated during eye movements but rarely appeared in attentive tracking.

Nonetheless, the similarities and differences between attention and eye movements are very intriguing. Although our comparison was preliminary, we found common regions of activation between attentive tracking and eye movements, particularly in MT+, the IPS and FEF. Corbetta (1998) recently performed a meta-analysis of previous attention and saccadic eye-movement studies and observed a substantial degree of overlap between the two tasks. He also provided preliminary data from a single subject showing virtually identical activation for both tasks and emphasized their similarity. However, our within-subject comparisons provide evidence for qualitative and quantitative differences in activation between the two tasks and also include activity produced by smooth pursuit. Anterior parietal cortex was activated more by attention, whereas posterior parietal cortex (near the parieto-occipital border) was activated more by eye movements. Brandt et al. (1997a) have since directly com- pared attentive tracking and smooth pursuit using comparable stimuli in the same subjects and found further evidence for such activation differences. Our results also suggest that attentive tracking shares more overlap with saccades than with smooth pursuit.

Given that attentional activation is not due to spurious eye movements, three interesting explanations remain for the high degree of functional overlap between attention and eye movements. First, attention may be required in the planning of eye movements (Hoffman and Subramaniam 1995; Khurana and Kowler 1987; Kowler et al. 1995), particularly for unpredictable saccades that shared more activation with attentive tracking than did smooth pursuit. Second, attention and eye movements may be intimately linked processes. Such functional overlap has been demonstrated convincingly in the macaque lateral intraparietal sulcus (LIP) (Colby et al. 1996) or " parietal eye field" (Andersen et al. 1992), which may have its human homologue in the anterior IPS (Müri et al. 1996). Indeed, all four of our subjects who performed eye-movement tasks showed an activation focus in the anterior IPS that was common to both attentive tracking and saccades, though stronger for the attention task. In addition, while some have argued that the frontal eye fields are purely visuomotor areas (Paus 1996), others have found FEF modulation by cognitive factors (Bichot et al. 1996; O'Driscoll et al. 1995; Thompson et al. 1997). Third, visual attention may involve the covert planning and suppression of an eye movement (Rizzolatti et al. 1994; Snyder et al. 1997); although, behavioral evidence suggests attention and eye movements can be dissociated (Klein 1980; Klein and Pontefract 1994). Certain regions, such as the FEFs, could be involved in either the planning stages of the eye movement and/or the act of suppressing it. These different interpretations may not be mutually exclusive. Data from a parametric study of attentive tracking suggested that an eye-movement planning/suppression hypothesis could account for parametric functions in a several areas (superior parietal lobe, precuneus, and possibly the FEF) but certainly not all (Culham et al. 1997c).

Activation due to attentive tracking also may overlap with that from motor planning other than eye movements. A study by Grafton et al. (1992) found similar regions of activation (FEF, precuneus, dorsal parietal cortex, SMA) when subjects physically tracked moving targets with their index fingers (or even with their toes or tongues!) compared with a control condition of visual tracking (smooth pursuit). Their results could not be accounted for by general attentional difficulty, though they may nonetheless have involved spatial attention and memory. Indeed, several of the regions we observed also have been identified in studies of spatial memory, including PET foci, which appear to correspond to the FEF, IPS/PCS, superior parietal cortex, and lateral occipitoparietal junction (posterior IPS or V3A) (Courtney et al. 1996; Jonides et al. 1993). Others have observed that two of these regions (anterior IPS, lateral occipitoparietal junction) are activated by both object-oriented action and object recognition, leading to the suggestion that they are responsible for spatial analyses of objects (Faillenot et al. 1997). Clearly, activation in these areas is not highly specific to any particular task; the challenge facing neuroimaging is to determine which factors are crucial in which areas. 


\section{Attentive tracking and motion processing}

In addition to activation in parietal and frontal areas, we also observed attentional modulation in $\mathrm{MT}+$, a result consistent with past reports of its susceptibility to attentional influences (Beauchamp 1997; Bush et al. 1995; Corbetta et al. 1990, 1991; O'Craven et al. 1997; Rees et al. 1997). In these previous reports, however, attention was directed to arrays of targets (squares or random dots). Here we have shown that attention to individual moving targets also can activate the motion complex. Indeed, recent physiological evidence suggests that attention to the motion of a group of dots within an MT receptive field produces relatively modest modulation (Seidemann and Newsome 1997) compared with attention directed toward a specific target (Treue and Maunsell 1996). However, the aggregate regional response measured by fMRI also may include suppression of motion responses to the moving distractors, which could account for the relatively weak effects we observed.

We were somewhat surprised that MT+ did not respond significantly more strongly to attentive tracking than to attention shifting. Given that subjects have a percept of motion in the tracking but not shifting conditions and the evidence that $\mathrm{MT}+$ correlates with the percept of motion (Tootell et al. 1995a; Zeki et al. 1993), we expected modulation in this visual motion complex. One possible explanation is that subjects sometimes perceived apparent motion between the counterphasing dots in the passive-viewing control condition (the ring of dots would appear to rock back and forth between positions) such that tracking may not have yielded significant enhancement.

Alternatively, the substrates responsible for the perception of apparent motion may occur at later stages in visual processing, perhaps in the parietal lobe (Dawson 1991). Areas responsive to visual motion have been reported in parietal cortex, in the IPS (Cheng et al. 1995) and PostCS (Dupont et al. 1994). These regions may be homologous to posterior parietal areas reported in the macaque that have properties well suited for attentive-tracking processes. For example, Assad and Maunsell (1995) reported that posterior parietal neurons were activated by the inferred motion of a target behind an occluder, a relatively high-level effect that was not dependent on the visual motion of the stimulus.

No attentional enhancement was observed for visual cortical areas (V1, V2, V3/VP, V3A). Past examinations of similar effects have been mixed. Some studies have reported early visual modulation by attention (e.g., Shulman et al. 1997), whereas others have not (e.g., O'Craven et al. 1997). This suggests that the effects are highly task-dependent (Watanabe et al. 1998; Worden et al. 1996), Watanabe and his colleagues (1998) compared a number of attention-to-motion tasks and found a dissociation in activation. Consistent with the present results, they reported MT + modulation for all such tasks but modulation in visual areas along the calcarine only when attention was directed to a local component of motion and not when it was directed to integrated object motion in a task similar to ours.

However, not all motion-processing areas were enhanced by attentive tracking. Responses were largely absent in two previously-reported motion-selective areas: retinotopic area
V3A (Tootell et al. 1997) and the superior temporal sulcus (Bonda et al. 1996).

In most of our subjects, attentive tracking activated a region of lateral occipital cortex between MT+ and V3A. This region may correspond to a lateral occipital region, area LO, which has been observed in tasks involving object recognition (Malach et al. 1995) or figure-ground segregation (Mendola et al. 1997). Alternatively, it may correspond to a separate kinetic occipital area (KO), which one group has reported as being particularly responsive to kinetic boundaries (Van Oostende et al. 1997; but see also Reppas et al. 1997). Yantis (1992) has suggested that attentive tracking involves perceptual grouping to form a virtual shape the vertices of which are defined by tracked items. Thus our attentive-tracking task may have recruited areas in this vicinity that are involved in shape processing or image segmentation.

\section{General conclusions}

We have investigated the neural substrates underlying an attention-based process that is used to track targets as they move. Our results indicate that the parietal lobes are involved fundamentally in this high-level process, which links attention to motion perception to determine "which one went where." This suggestion is corroborated by theoretical modeling (Dawson 1991), neurophysiology (Assad and Maunsell 1995), psychophysics (Culham et al. 1998), and neuropsychology (Michel et al. 1997). In addition, attentive tracking activates $\mathrm{MT}+$, consistent with the perception of motion arising from attentive tracking (Cavanagh 1992; Lu and Sperling 1995).

Although attentive tracking is theoretically distinct from attention shifting, saccades, and smooth-pursuit eye movements, a surprising amount of neuroanatomic overlap was observed between the four processes. In addition, these areas are similar to those observed in tasks that involve spatial memory (Courtney et al. 1996; Jonides et al. 1993), shape processing (Faillenot et al. 1997), and motor tracking (Grafton et al. 1992). Although these tasks typically have been studied in isolation, their common activation patterns suggest that they share neural substrates that are not responsible for highly specialized functions such as attention shifting but rather participate in common higher-order functions. These may include more general processes such as the localization of targets in spatial coordinate frames (Andersen et al. 1997) or the coordination of attentional and intentional processes (Colby 1996; Snyder et al. 1997).

We are grateful to J. Intriligator for providing the programming code used to generate the stimuli. We thank many people who provided assistance, instruction, participation, and advice: K. Hall, N. Hadjikhani, E. Wojciulik, T. Watanabe, J. McDermott, M. Chun, O. Weinrib, A. Jiang, K. Kwong, G. Bush, C. Moore, J. Mendola, R. Wenzel, T. Takahashi, R. Savoy, K. O'Craven, P. Ledden, M. Vevea, M. Foley, T. Campbell, R. Comtois, B. Rosen. and an anonymous reviewer.

This research was supported by National Institutes of Health Grants EY09258 to P. Cavanagh, MH-56037 to N. G. Kanwisher, and EY-07980 and a Human Frontiers Science Program grant to R.B.H. Tootell, DFG (Germany) Grant BR1691/1-1 to S. A. Brandt, and a grant from the McDonnell-Pew Program in Cognitive Neuroscience to J. Culham.

Present address and address for reprint requests: J. Culham, Dept. of Psychology, University of Western Ontario, Social Science Centre, London, Ontario N6A 5C2, Canada. 
E-mail: culham@irus.rri.uwo.ca

Received 4 May 1998; accepted in final form 27 July 1998.

\section{REFERENCES}

Andersen, R. A., Brotchie, P. R., And Mazzoni, P. Evidence for the lateral intraparietal area as the parietal eye field. Curr. Opin. Neurobiol. 2: 840-846, 1992

Andersen, R. A., Snyder, L. H., Bradley, D. C., And Xing, J. Multimodal representation of space in the posterior parietal cortex and its use in planning movements. Annu. Rev. Neurosci. 20: 303-330, 1997.

Anstis, S. M. The perception of apparent movement. Philos. Trans. R. Soc. Lond. B Biol. Sci. 290: 153-168, 1980.

Assad, J. A. And Maunsell, J. H. R. Neuronal correlates of inferred motion in primate posterior parietal cortex. Nature 373: 518-521, 1995.

BALINT, R. Seelenlähmung des "Schauens,' optische Ataxie räumliche, Störung der Aufmerksamkeit Psychiat. Monatsschr. Psychiatr. Neurol. 25: $51-81,1909$.

Beauchamp, M. S., Cox, R. W., And DeYoe, E. A. Graded effects of spatial and featural attention on human area MT and associated motion processing areas. J. Neurophysiol. 78: 516-520, 1997.

Bichot, N. P., Schall, J. D., AND Thompson, K. G. Visual feature selectivity in frontal eye fields induced by experience in mature macaques. Nature 381: 697-699, 1996.

Bonda, E., Petrides, M., Ostry, D., And Evans, A. Specific involvement of human parietal systems and the amygdala in the perception of biological motion. J. Neurosci. 16: 3737-3744, 1996.

BRADDICK, O. J. Low-level and high-level processes in apparent motion. Philos. Trans. R. Soc. Lond. B Biol. Sci. 290: 137-151, 1980.

Brandt, S. A., Dale, A. M., Wenzel, R., Culham, J. C., Mendola, J. D., AND ToOTELL, R.B.H. Sensory, motor and attentional components of eye movement related activation as revealed by fMRI. Soc. Neurosci. Abstr. 23: 2223, 1997a.

Brandt, S. A., Reppas, J. Dale, A., Wenzel, R., Savoy, R., and Tootell, R. Simultaneous infra-red oculography and fMRI (Abstract). Proc. Int. Soc. Magn. Reson. Med. 3: 1978, 1997b.

Bush, G., Rosen, B., Belliveau, J., Reppas, J., Rauch, S. L., Kennedy, D., Sutton, J. And Tootell, R. A functional magnetic resonance study of selective and divided attention during visual discriminations of shape, speed and color. Soc. Neurosci. Abstr. 21: 936, 1995.

Carter, C. S., Braver, T. S., Barch, D. M., Botvinick, M. M., Noll, D., And Cohen, J. D. Anterior cingulate cortex, error detection, and the online monitoring of performance. Science 280: 747-749, 1998.

Cavanagh, P. Short-range vs. long-range motion: not a valid distinction. Spat. Vision 5: 303-309, 1991

Cavanagh, P. Attention-based motion perception. Science 257: 1563 $1565,1992$.

Cavanagh, P. And Mather, G. Motion: the long and short of it. Spat. Vision 4: 103-129, 1989

Cavanagh, P., Tyler, C. W., and Favreau, O. E. Perceived velocity of moving chromatic gratings. J. Opt. Soc. Am. A 1: 893-899, 1984.

Cheng, K., Fujita, H., Kanno, I., Miura, S., and Tanaka, K. Human cortical regions activated by wide-field visual motion: an H215O PET study. J. Neurophysiol. 74: 413-427, 1995.

Chun, M. M. And Cavanagh, P. Seeing two as one: linking apparent motion and repetition blindness. Psychol. Sci. 8: 74-79, 1997.

Colby, C. L. A neurophysiological distinction between attention and intention. In: Attention and Performance XVI, edited by T. Inui and J. L. McClelland. Cambridge MA: MIT Press, 1996, p. 157-180.

Colby, C. L., Duhamel, J. R., And GoldberG, M. E. Visual, presaccadic, and cognitive activation of single neurons in monkey lateral intraparietal area. J. Neurophysiol. 76: 2841-2852, 1996.

CorbetTA, M. Frontoparietal cortical networks for directing attention and the eye to visual locations: identical, independent or overlapping neural systems? Proc. Natl. Acad. Sci. USA 95: 831-838, 1998.

Corbetta, M., Miezin, F. M., Dobmeyer, S., Shulman, G. L., And PetERSEN, S. E. Attentional modulation of neural processing of shape, color and velocity in humans. Science 248: 1556-1559, 1990.

Corbetta, M., Miezen, F. M., Dobmeyer, Shulman, G. L., and PetERSEN, S. E. Selective and divided attention during visual discriminations of shape color, and speed: functional anatomy by positron emission tomography. J. Neurosci. 11: 2383-2402, 1991.

Corbetta, M., Miezin, F. M., Shulman, G. L., and Petersen, S. E. A PET study of visuospatial attention. J. Neurosci. 13: 1202-1226, 1993.
Corbetta, M., Shulman, G. L., Miezin, F. M., and Petersen, S. E. Superior parietal cortex activation during spatial attention shifts and visual feature conjunctions. Science 270: 802-805, 1995.

Courtney, S. M., Ungerleider, L. G., KeIl, K., And Haxby, J. V. Object and spatial memory activate separate neural systems in human cortex. Cereb. Cortex 6: 39-49, 1996.

Culham, J. C., Brandt, S. A., Wenzel, R., Cavanagh, P., Dale, A. M., AND TOOTELL, R.B.H. Attentive tracking of moving targets and eye movements produce overlapping but distinct fMRI activation in occipitoparietal cortex. Cognit. Neurosci. Soc. Abstr. 28, 1997a.

Culham, J. C. And Cavanagh, P. Motion capture of luminance stimuli by equiluminant color gratings and by attentive tracking. Vision Res. 34: 2701-2706, 1994.

Culham, J. C., Cavanagh, P., Kanwisher, N. G., Brandt, S., Dale, A. M., AND ToOTELL, R.B.H. Attentive tracking of moving targets produces parietal activation revealed by functional magnetic resonance imaging (Abstract). Invest. Opthalmol. Visual Sci. 38 Suppl. : 1174, 1997b.

Culham, J., Cavanagh, P., Kanwisher, N., Intriligator, J., and NaKayAMA, K. Varying attentional load produces different fMRI task response functions in occipitoparietal cortex and frontal eye fields. Soc. Neurosci. Abstr. 23: 1119, 1997c.

Culham, J. C., Nishida, S., Ledgeway, T., Cavanagh, P., von Grünau, M. W., Kwas, M., Alais, D., And Raymond, J. E. Higher order motion aftereffects. In: The Motion After-Effect: A Modern Prospective, edited by G. Mather, F. Verstraten, and S. Anstis. Cambridge, MA: MIT Press, 1998, p. 85-124.

DAle A., M. AND BucKner R. L. Selective averaging of rapidly presented individual trials using fMRI. Hum. Brain Map. 5: 329-340, 1997.

Dale, A. M. AND Sereno, M. I. Improved localization of cortical activity by combining EEG and MEG with MRI cortical surface reconstruction: a linear approach. J. Cognit. Neurosci. 5: 162-176, 1993.

DAwson, M.R.W. The how and why of what went where in apparent motion: modeling solutions to the motion correspondence problem. Psychol. Rev. 98: 569-603, 1991.

De Yoe, E. A., Carman, G. J., Bandettini, P., Glickman, S., Wieser, J., Cox, R., Miller, D., AND Netz, J. Mapping striate and extrastriate visual areas in human cerebral cortex. Proc. Natl. Acad. Sci. USA 93: 2382 2386, 1996.

Dupont, P., Orban, G. A., De Bruyn, B., Verbruggen, A., And MortelMANS, L. Many areas in the human brain respond to visual motion. $J$. Neurophysiol. 72: 1420-1424, 1994.

Duvernoy, H. The Human Brain: Surface, Three-Dimensional Sectional Anatomy and MRI. New York: Springer-Verlag, 1991.

Drury, H. A., Van Essen, D. C., Anderson, C. H., Lee, C. W., Coogan, T. A., AND LEWIS, J. W. Computerized mappings of the cerebral cortexa multiresolution flattening method and surface-based coordinate system. J. Cognit. Neurosci. 8: 1-28, 1996.

Engel, S. A., Glover, G. H., And Wandell, B. A. Retinotopic organization in human visual cortex and the spatial precision of functional MRI. Cereb. Cortex 7: 181-192, 1997.

Faillenot, I., Sakata, H., Costes, N., Decety, J., and Jeannerod, M. Visual working memory for shape and 3D-orientation; a PET study. Neuroreport 8: 859-862, 1997.

Grafton, S. T., Mazziotta, J. C., Woods, R. P., and Phelps, M. E. Human functional anatomy of visually guided finger movements. Brain 115 565-587, 1992.

Helmholtz, H. Helmholtz's Treatise on Physiological Optics (3rd. ed.), edited by J.P.C. Southhall. Menasha, WI: Optical Society of America, $1867 / 1925$.

Hoffman, J. E. AND Subramaniam, B. Saccadic eye movements and visual selective attention. Percept. Psychophys. 57: 787-795, 1995.

INTRILIGATOR, J. AND CAVANAGH, P. An object-specific spatial attentional facilitation that does not travel to adjacent spatial locations (Abstract). Invest. Ophthalmol. Visual Sci. 33 Suppl.: 1263, 1992.

Jiang, A., Kennedy, D. N., Baker, J. R., Weisskoff, R. M., Tootell, R.B.H., Woods, R. P., Benson, R. R., Kwong, K. K., Brady, T. J., RoSen, B. R., AND Belliveau, J. W. Motion detection and correction in functional MR imaging. Hum. Brain Map. 3: 224-235, 1995.

Jonides, J., Smith, E. E., Koeppe, R. A., Awh, E., Minoshima, S., And Mintun, M. A. Spatial working memory in humans as revealed by PET Nature 363: 623-625, 1993.

Kahneman, D., Treisman, A. And Gibbs, B. J. The reviewing of object files: object-specific integration of information. Cognit. Psychol. 24: 175219, 1992 
KhuRANA, B. AND Kowler, E. Shared attentional control of smooth eye movement and perception. Vision Res. 27: 1603-1618, 1987.

KLEIN, R. M. Does oculomotor readiness mediate cognitive control of visual attention? In: Attention and Performance VIII, edited by R. Nickerson. Hillsdale, NJ: Erlbaum, 1980, p. 259-276.

Klein, R. M. and Pontefract, A. Does oculomotor readiness mediate cognitive control of visual attention? Revisited! In: Attention and Performance $X V$, edited by $\mathrm{C}$. Umilta and $\mathrm{M}$. Moscovitch. Cambridge, MA: MIT Press. 1994, p. 333-350.

Kowler, E., Anderson, E., Dosher, B., and Blaser, E. The role of attention in the programming of saccades. Vision Res. 35: 1897-1916, 1995.

Lu, Z. AND SPERLING, G. Attention-generated apparent motion. Nature 377: 237-239, 1995.

Malach, R., Reppas, J. B., Benson, R. R., Kwong, K. K., Jiang, H., KenNedy, W. A., Ledden, P. J., Brady, T. J., Rosen, B. R., And Tootell, R.B.H. Object-related activity revealed by functional magnetic resonance imaging in human occipital cortex. Proc. Nat. Acad. Sci. USA 92: 8135 8139, 1995.

Mendola, J. D., Dale, A. M., Liu, A. K., And Tootell, R.B.H. The representation of illusory contours in human visual cortex revealed by fMRI (Abstract). Invest. Ophthalmol. Visual Sci. 38 Suppl.: 204, 1997.

Michel, F., Henaff, M. A., And Intriligator, J. Posterior callosum split and left parietal lesion reveal visual deficits in the right visual field. Cognit. Neurosci. Soc. Abstr. 22: 1856, 1997.

MiYaUChI, S., SASAKI, Y., PÜtZ, TAKINo, IMAmizu, and OKamoto. Activation of parieto-occipital junction and superior parietal cortex during visual search task. Soc. Neurosci. Abstr. 22: 1856, 1996.

Müri, R. M., Iba-Zizen, M. T., Derosier, E. A., Cabanis, E. A., And PierROT-DeSEILLIGNY, C. Location of the human posterior eye field with functional magnetic resonance imaging. J. Neurol. Neurosurg. Psychiatry 60: 445-448, 1996.

O'Craven, K. M., Rosen, B. R., Kwong, K. K., Treisman, A., and SAvoY, R. L. Voluntary attention modulates fMRI activity in human MTMST. Neuron 18: 591-598, 1997.

O’Driscoll, G. A., Alpert, N. M., Matthysse, S. W., Levy, D. L., RAUCH, S. L., AND Holzman, P. S. Functional neuroanatomy of antisaccade eye movements investigated with positron emission tomography. Proc. Natl. Acad. Sci. USA 92: 925-929, 1995.

Paus, T. Location and function of the human frontal eye-field: a selective review. Neuropsychologia 34: 475-483, 1996.

Petit, L., Clark, V. P., Ingeholm, J., and Haxby, J. V. Dissociation of saccade-related and pursuit-related activation in human frontal eye fields as revealed by fMRI. J. Neurophysiol. 77: 3386-3390, 1997.

Petit, L., Orssaud, C., Tzourio, N., Crivello, F., Berthoz, A., And MAZOYER, B. Functional anatomy of a prelearned sequence of horizontal saccades in humans. J. Neurosci. 16: 3714-3726, 1996.

Petit, L, Tzourio, N., Orssaud, C., Pietrzyk, U., Berthoz, A., And MAZOYER, B. Functional neuroanatomy of the human visual fixation system. Eur. J. Neurosci. 7: 169-174, 1995.

Posner, M. I. Orienting of attention. Q. J. Exp. Psychol. 32: 3-25, 1980.

Posner, M. I. and Petersen, S. E. The attention system of the human brain. Annu. Rev. Neurosci. 13: 25-42, 1990.

Posner, M. I., Petersen, S. E., Fox, P. T., and Raichle, M. E. Localization of cognitive operations in the human brain. Science 240: $1627-$ $1631,1988$.

Pylyshyn, Z. A role of location indexes in spatial perception: a sketch of the FINST spatial index model. Cognition 32: 65-97, 1989.

Pylyshyn, Z. Some primitive mechanisms of spatial attention. Cognition 50: 363-384, 1994.

Pylyshyn, Z. W. AND STORM, R. W. Tracking multiple independent targets: evidence for a parallel tracking mechanism. Spat. Vision 3: 179-197, 1988

ReEs, G., Frith, C. D., AND LAVIE, N. Modulating irrelevant motion perception by varying attentional load in an unrelated task. Science 278: 16161619. 1997.

Reppas, J. B., Niyogi, S., Dale, A. M., Sereno, M. I., and Tootell, R. B.
Representation of motion boundaries in retinotopic human visual cortical areas. Nature 388: 175-179, 1997.

Rizzolatti, G., Riggio, L., And Sheliga, B. M. Space and selective attention. In: Attention and Performance $\mathrm{XV}$, edited by $\mathrm{C}$. Umilt $\$$ and $\mathrm{M}$. Moscovitch. Cambridge, MA: MIT Press, 1994, p. 231-265.

Scholl, B. J. AND PyLyshyn, Z. W. Tracking multiple items through occlusion: clues to visual objecthood. Cognitive Psychology (In press).

Seidemann, E. And Newsome, W. T. Influence of spatial attention on the responses of area MT neurons. Soc. Neurosci. Abstr. 23: 302, 1997.

Sereno, M. I., Dale, A. M., Reppas, J. B., Kwong, K. K., Belliveau, J. W., Brady, T. J., Rosen, B. R., AND Tootell, R.B.H. Borders of multiple visual areas in humans revealed by functional magnetic resonance imaging. Science 268: 889-893, 1995.

ShioIRI, S. AND CAVANAGH, P. Localizing the object tracked by attention (Abstract). Invest. Ophthalmol. Visual Sci. 37 Suppl. S213, 1996.

Shulman, G. L., Corbetta, M., Buckner, R. L., Raichle, M. E., Fiez, J. A., Miezen, F. M., AND Petersen, S. E. Top-down modulation of early sensory cortex. Cereb. Cortex 7: 193-206, 1997.

SNyder, L. H., Batista, A. P., AND ANDERSEn, R. A. Coding of intention in the posterior parietal cortex. Nature 386: 167-170, 1997.

Talairach, J. And Tournoux, P. Co-Planar Stereotaxic Atlas of the Human Brain: 3-Dimensional Proportional System: An Approach to Cerebral Imaging. Stuttgart, Germany: Georg Thieme Verlag, 1988.

ThOMPSON, K. G., BICHOT, N. P., AND Schall, J. D. Dissociation of visual discrimination from saccade programming in macaque frontal eye field. J. Neurophysiol. 77: 1046-1050, 1997.

Treisman, A. The perception of features and objects. In: Attention: Selection, Awareness, and Control, edited by A. Baddeley and L. Weiskrantz. Oxford: Clarendon, 1993, p. 5-35.

Treisman, A. and Gelade, G. A feature integration theory of attention. Cognit. Psychol. 12: 97-136, 1980.

Treue, S. And Maunsell, J.H.R. Attentional modulation of visual motion processing in cortical areas MT and MST. Nature 382: 539-541, 1996.

Tootell, R.B.H., Dale, A. M., Sereno, M. I., and Malach, R. New images from human visual cortex. Trends Neurosci. 19: 481-489, 1996.

Tootell, R.B.H., Mendola, J. D., Hadjikhani, N. K., Ledden, P. J., Liu, A. K., Reppas, J. B., Sereno, M. I., AND Dale, A. M. Functional analysis of V3A and related areas in human visual cortex. J. Neurosci. 17: 70607078, 1997.

ToOtell, R.B.H., Reppas, J. B., Dale, A. M., LoOK, R. B., Sereno, M. I., Malach, R., BRady, T. J., ANd Rosen, B. R. Visual motion aftereffect in human cortical area MT revealed by functional magnetic resonance imaging. Nature 375: 139-141, 1995a.

Tootell, R.B.H., Reppas, J. B., Kwong, K. K., Malach, R., Born, R. T., Brady, T. J., Rosen, B. R., and Belliveau, J. W. Functional analysis of human MT and related visual cortical areas using magnetic resonance imaging. J. Neurosci. 15: 3215-3230, 1995b.

Van Oostende, S., Sunaert, S., Van Hecke, P., Marchal, G., and Orban, G. The kinetic occipital (KO) region in man: an fMRI study. Cereb. Cortex 7: 690-701, 1997.

Watanabe, T., Sasaki, Y., Miyauchi, S., Putz, B., Fujimaki, T., Nielsen, M., Takino, R., and Miyakawa, S. Attention-regulated activity in human primary visual cortex. J. Neurophysiol. 79: 2218-2221, 1998.

WERTHEIMER, M. Experimentelle Studien über das Sehen von Bewegung. Zeitschr. Psychol. 61: 161-265. Partial English translation in: Classics in Psychology, edited by Thorne Shipley. New York: Philosophical Library, 1912/1961, p. 1032-1089.

WOJCIULIK, E. AND KANWISHER, N. A general visual attention mechanism in the human brain: evidence from fMRI (Abstract). NeuroImage 7: S78, 1998.

Worden, M., Schneider, W., And Wellington, R. Determining the locus of attentional selection with functional magnetic resonance imaging ( $\mathrm{Ab}$ stract). NeuroImage 3: S244, 1996.

YANTIS, S. Multielement visual tracking: attention and perceptual organzation. Cognit. Psychol. 24: 295-340, 1992.

Zeki, S., Watson, J.D.G., and Frackowiak, R.S.J. Going beyond the information given: the relation of illusory visual motion to brain activity. Proc. R. Soc. Lond. B Biol. Sci. 252: 215-222, 1993. 